\title{
1 Future fish distributions constrained by depth in warming seas
}

2

3 Louise A. Rutterford ${ }^{1,2,3 \dagger}$, Stephen D. Simpson ${ }^{1,+, *}$, Simon Jennings ${ }^{3,4}$, Mark P. Johnson ${ }^{5}$,

4 Julia L. Blanchard ${ }^{6}$, Pieter-Jan Schön ${ }^{7}$, David W. Sims ${ }^{8,9,10}$, Jonathan Tinker $^{11}$ \&

5 Martin J. Genner ${ }^{2}$

6

1 Biosciences, College of Life \& Environmental Sciences, University of Exeter, Stocker Road, Exeter, EX4 4QD, United Kingdom.

2 School of Biological Sciences, Life Sciences Building, University of Bristol, Bristol, BS8 1TQ, United Kingdom.

3 Centre for Environment Fisheries and Aquaculture Science (Cefas), Lowestoft Laboratory, Pakefield Road, Lowestoft, Suffolk, NR33 OHT, United Kingdom.

4 School of Environmental Sciences, University of East Anglia, Norwich, NR4 7TJ, United Kingdom.

5 Ryan Institute, National University of Ireland Galway, University Road, Galway, Ireland.

6 Institute of Marine and Antarctic Studies, University of Tasmania, IMAS Waterfront Building, 20 Castray Esplanade, Battery Point, Hobart, TAS 7001, Australia.

7 Agri-Food and Biosciences Institute, Newforge Lane, Belfast, BT9 5PX, Northern Ireland, United Kingdom.

8 Marine Biological Association of the United Kingdom, The Laboratory, Citadel Hill, Plymouth, PL1 2PB, United Kingdom.

9 Ocean and Earth Science, National Oceanography Centre Southampton, University of Southampton, Waterfront Campus, European Way, Southampton, SO14 3ZH, United Kingdom.

10 Centre for Biological Sciences, Building 85, University of Southampton, Highfield Campus, Southampton, SO17 1BJ, United Kingdom.

11 Met Office Hadley Centre, FitzRoy Road, Exeter, Devon, EX1 3PB, United Kingdom.

† L.A.R. and S.D.S contributed equally to this work

* Correspondence should be addressed to S.D.S. (S.Simpson@exeter.ac.uk) 
European continental shelf seas have experienced intense warming over the last $\mathbf{3 0}$ years $^{1}$. In the North Sea, fishes have been comprehensively monitored throughout this period and resulting data provide a unique record of changes in distribution and abundance in response to climate chang $\mathrm{e}^{2,3}$. We use these data to demonstrate the remarkable power of Generalised Additive Models (GAMs), trained on data earlier in the time-series, to reliably predict trends in distribution and abundance in later years. Then, challenging process-based models that predict substantial and ongoing poleward shifts of cold-water species ${ }^{4,5}$, we find that GAMs coupled with climate projections predict future distributions of demersal (bottom-dwelling) fish species over the next $\mathbf{5 0}$ years will be strongly constrained by availability of habitat of suitable depth. This will lead to pronounced changes in community structure, species interactions and commercial fisheries, unless individual acclimation or populationlevel evolutionary adaptations enable fish to tolerate warmer conditions or move to previously uninhabitable locations.

While the temperature of the world's oceans has gradually risen through the $20^{\text {th }}$ Century, the northeast Atlantic has experienced particularly intense warming, resulting in the North Sea mean annual sea-surface temperature increasing by $1.3^{\circ} \mathrm{C}$ over the last 30 years ${ }^{1}$, a rate four times faster than the global average ${ }^{6}$. Predictions for the North Sea suggest a further $1.8^{\circ} \mathrm{C}$ rise in sea-surface temperatures during the next five decades (Hadley Centre QUMP_ens_00 model, unpublished data supplied by J. Tinker) (Fig. 1). Impacts of recent warming on northeast Atlantic marine ecosystems have been diverse, including reorganisation of the plankton community ${ }^{7}$, modification to the phenology of fish spawning ${ }^{8,9}$, and alterations of ecosystem interactions ${ }^{10,11}$. Due to its longstanding economic importance to fisheries (reported landings in 2007 valued at $\$ 1.2$ billion $^{1}$ ) and other industries, the ecology of the North Sea has been intensively monitored throughout this period of recent warming. 
61 Analyses of North Sea fish surveys have revealed northerly range expansions of warmer-

62 water species $^{12}$, population redistributions to higher latitudes ${ }^{2}$ and deeper water ${ }^{13}$, and

63 widespread changes in local abundance associated with warming, with impacts on

64 community structure ${ }^{3}$. This substantial modification to fish community composition in the

65 region has had an observable economic impact on fisheries, with landings of cold-adapted

66 species halved but landings of warm-adapted species increasing 2.5 times since the $1980 \mathrm{~s}^{3}$;

67 a pattern also identified in other marine ecosystems ${ }^{14}$. With a uniquely rich fish abundance

68 time-series from the period of warming, it is possible to split these data to assess how

69 predictions made using data from earlier years match observations from later years; a

70 validation approach which has been promoted for terrestrial systems ${ }^{15}$. Existing studies have

71 used survey data to describe past changes ${ }^{2,3,12,13}$, or adopted process-based climate

72 envelope models to predict future abundance without validation ${ }^{16}$. Thus there is a need to

73 compare the predictions of climate-envelope models with those from more structurally-

74 complete data-driven models that have been developed and tested using spatially and

75 temporally explicit abundance data.

77 The GAM approach makes no a-priori assumptions about the nature of associations between predictors and response variables ${ }^{17}$ and has been used to assess the importance of different environmental drivers on patterns of distributions and relative abundance in marine ecosystems ${ }^{18-20}$. Here we developed GAMs to predict changes in the distribution and abundance of the 10 most abundant North Sea demersal (bottom-dwelling) fish species, which accounted for $68 \%$ of commercial landings by the North Sea fishery between 1980 and 2010 (www.ices.dk/marine-data/dataset-collections/Pages/Fish-catch-and-stockassessment.aspx). We used a two-step approach. First, predictive models with different sets of variables were compared using data earlier in the time-series to train the models and predict known distributions and abundances later in the time-series. Second, models were used to predict changes in species distributions over the next 50 years. 
Predictors of species' abundance were identified from a wider array of potential variables (annual sea-surface and near-bottom temperatures; seasonal sea-surface and near-bottom temperatures; depth; salinity; fishing pressure: all of which are expected to influence fish abundance and distribution ${ }^{\text {e.g. } 2,3,13,21}$ ). For each species we calculated from summer and winter monitoring surveys the mean annual abundance per grid cell in a 10 year time-slice (2000-2009, inclusive) and used these data to train GAM models based on different combinations of variable sets to predict the same data. We then analysed associations between the predictions and original observations. All model combinations performed well with predictions against known data all exceeding correlation coefficients of 0.67 and only marginal changes with the loss of each variable for each species (Supplementary Table 1). Following an assessment of the performance of alternate GAMs (Supplementary Figure 4, Supplementary Tables 1 and 2), a model that included temperature, depth and salinity variables was applied to each species (Fig. 2a and Supplementary Table 1). The selected models excluded the metric for fishing pressure since this was a relatively poor predictor variable in the majority of cases (Fig. 2a and Supplementary Table 1).

To assess the most appropriate length of time-series to use for future projections, we developed models to predict the abundance of species across the region in a decade using annual and seasonal temperature, salinity and depth data from the periods 10, 20 and 30 years beforehand. There was no consistent improvement in model fit with increasing periods of training data (Fig. 2b and Supplementary Fig. 1), thus we used 10-year training periods for all subsequent projections. The final stage of the model development stage was to assess the ability of GAMs, using an effective set of variables, to predict distributions for 10 , 20 and 30 year periods into the future and compare with observations. Predictions closely matched observations for 8 of the 10 species using both survey datasets (Fig. 2c and Supplementary Fig. 1). 
116 Following model development and testing, models trained on data from 2000-2009 were

117 used to predict future distributions, abundance and thermal occupancy of the eight species

118 for which the models were effective, based on environmental conditions forecasted with the

119 Hadley Centre QUMP_ens_00 model (Fig. 3 and Supplementary Fig. 1). Predictions based

120 on independent winter and summer fish surveys showed congruent temperature occupancy

121 patterns, with species predicted to experience warmer conditions and maintain existing

122 distributions, rather than maintaining their preferred temperature ranges by redistributing to

123 other locations (Fig. 3).

124

125 We quantified latitudinal ranges, a commonly used estimator of distributions, which showed

126 considerable overlap between present and future conditions, with no consistent pattern

127 among species in predicted changes in distributions (Fig. 3). This indicates that poleward

128 advances of North Sea demersal fishes following preferences for colder waters are unlikely

129 to be commonplace, and highlights how process-based models that predict northward shifts

130 may underestimate dependence on non-thermal habitat. Importantly, predicted depth ranges

131 were also similar for present and future conditions (Fig. 3), implying that depth-associated

132 niches are the primary drivers and constraints of the distributions of demersal species. One

133 species predicted here to have the most marked reduction in abundance alongside a

134 proportionate increase in individuals in deeper water was dab (Fig. 3). As a shallow water

135 species predominantly found in the southern North Sea their current thermal experience is

136 expected to be exceeded through the projection period (Supplementary Fig. 2.) suggesting

137 that expected climate change may force the species into less optimal habitats.

139 Seasonal temperatures, depth and salinity and likely co-varying habitat variables, appear to

140 be major determinants of current species distributions of commercially-important demersal

141 species in the North Sea, and were good predictors of past changes in distribution for many

142 species. Looking to the future, our results suggest that the strong associations of species

143 with specific habitats may ultimately prevent further poleward movement of species in 
144 response to warming as previously predicted ${ }^{16}$. A recent study demonstrated that $1.6^{\circ} \mathrm{C}$ of

145 warming across the European continental shelf over the last 30 years locally favoured some

146 demersal species suited to warmer waters, but drove local declines in cold-adapted species,

147 despite long-term stability in spatial patterns of species presence-absence ${ }^{3}$. Dependence of

148 species on specific non-thermal habitat, together with spatially-contrasting local changes in

149 responses to warming ${ }^{3}$, may explain why mean latitudinal range shifts are only apparent in

150 some species ${ }^{2}$, and are not detected in others despite sharing similar temperature

151 preferences. Dependence on specific non-thermal habitat has been observed in tagged

152 Atlantic cod (Gadus morhua), where fish occupied suboptimal thermal habitat for extended

153 periods with likely costs to metabolism and somatic growth ${ }^{22}$. Indeed a dominant driver of

154 changes in the central distributions of cod in the North Sea appears to have been intense

155 fishing pressure over the last century rather than warming, which has depleted former

156 strongholds in the western North Sea, driving an eastward longitudinal shift in relative

157 population abundance but no apparent poleward shift ${ }^{21}$. These factors, together with

158 potential indirect effects of warming potentially not captured in our models, for example from

159 changes to prey abundance, may explain why models based on depth and temperature

160 were not effective for longer term projections for Atlantic cod and whiting (Merlangius

161 merlangus). It is necessary to evaluate the performance of alternate predictor variables for

162 data-driven models of these species.

164 Mean depth distributions of North Sea fishes that had preferences for cooler water increased

165 by approximately $5 \mathrm{~m}$ during the warming of the 1980 s but tended to slow or stabilise

166 thereafter ${ }^{13}$. Based on the GAM results we do not expect or predict substantial further

167 deepening for cooler water species because depth is such a strong predictor of distribution.

168 Collectively, the studies imply that capacity to remain in cooler water by changing their depth

169 distribution has been largely exhausted in the 1980s and that fish with preferences for cooler

170 water are being increasingly exposed to higher temperatures, with expected physiological,

171 life history and population consequences. 
173 In the absence of substantial distributional shifts that would allow fish to occupy different

174 habitats and depths, North Sea populations are likely to experience $3.2^{\circ} \mathrm{C}$ of warming over

175 the coming century (J. Tinker, Hadley Centre). Although such temperature increases are

176 within observed thermal limits for these species the ecological consequences are unknown,

177 especially when warmer conditions are closer to thermal preferences of other species using

178 the same habitats. Furthermore, physiological theory suggests that responses of species to

179 projected warming will eventually reach thermal thresholds. As species' Pejus temperatures

180 are reached, increased metabolic costs will compromise growth with associated declines in

181 population productivity ${ }^{23}$. Capacity to tolerate warming will thus depend on scope for thermal

182 acclimation $^{24}$ and adaptation ${ }^{25}$, with the degree of connectivity between thermally-adapted

183 sub-populations across the geographic range of species influencing the rate of adaptation to

184 future warming. Unless adaptation or acclimation can track the rate of warming, it is likely

185 that stocks will be affected, both directly through individual physiological tolerances, and

186 indirectly through climate-related changes to the abundance of prey, predators, competitors

187 and pathogens.

189 Our study demonstrates the power of data-driven GAM models for predicting future fish

190 distributions. In contrast to process-based models that attempt to integrate discrete

191 ecological mechanisms such as dispersal and density dependence, GAMs are grounded by

192 past net responses of populations to all these processes, in addition to interspecific

193 interactions and habitat associations that are not typically considered in process-based

194 modelling, perhaps explaining the strong predictive power of our GAM approach for

195 predicting known future conditions. The results of this study suggest that we should be

196 cautious when interpreting process-based model projections of distributional shifts, and that

197 interpretations should be informed by data-driven modelling approaches, especially when

198 using predictions for policy and management planning. Our projections suggest that if

199 populations fail to adapt or acclimatise to a warmer environment, warming will change 
fishing opportunities for currently-targeted species in the North Sea over the next century.

201 Historically, fishing pressure has substantially modified the North Sea ${ }^{26}$ and ongoing

202 changes in management will play an important role in shaping future fisheries resources.

203 Species responses to temperature should be considered when planning future fisheries management strategies to ensure that anticipated long-term benefits of management are ecologically feasible in this period of intense warming.

206

\section{METHODS}

Fish surveys. We used two long-term monitoring surveys that give detailed descriptions of the distribution and abundance of demersal (bottom-dwelling) fishes in the North Sea. The

210 Centre for Environment, Fisheries and Aquaculture Science UK (Cefas) time-series is a

211 summer survey (August-September) conducted since 1980. The survey encompasses 69

$2121 \times 1^{\circ}$ latitude-longitude cells with at least three hauls conducted in each decade. The

213 International Council for the Exploration of the Sea (ICES) International Bottom Trawl Survey

214 (IBTS) time-series is a winter survey (January-March) conducted since 1980. The survey

215 encompasses $841 \times 1^{\circ}$ cells with at least three hauls conducted in each decade. Both

216 surveys are conducted using otter trawling gear (Granton trawl for pre-1992 Cefas surveys,

217 otherwise Grande Ouverture Verticale (GOV) trawls). Raw catch data were $4^{\text {th }}$-root

218 transformed to reduce skewness that is inherent in ecological abundance data.

220 Our study focused on the 10 most abundant demersal species targeted by commercial

221 fisheries or taken as bycatch (Fig. 2c), which together accounted for $68 \%$ of commercial

222 landings (by weight) in the North Sea fishery from 1980-2010 (www.ices.dk/marine-

223 data/dataset-collections/Pages/Fish-catch-and-stock-assessment.aspx). For both surveys,

224 we grouped data into three 10-year time slices and one three-year time slice for the 225 analyses: 1980-1989, 1990-1999, 2000-2009 and 2010-2012. The limited 2010-2012 time

226 slice was only used for testing predictions from the GAMs. To ensure a balanced design, 
mean values for each for each decadal time period were used. This method controls for the

228 variable numbers of survey hauls taken in each cell and ensures that longer-term responses

229 to climate change are identified rather than year on year variability. All data were $4^{\text {th }}$ root

230 transformed before being subject to GAM modelling, and individual cell predictions were

231 back transformed before calculation of correlation coefficients.

233 Depth. We used mean $1 \times 1^{\circ}$ cell in situ measures of depth taken during the hauls for each

234 survey (Supplementary Fig. 3), which closely matched data from the $1 \times 1^{\circ}$ resolution GEBCO

235 Digital Atlas (summer survey, $r=0.91$; winter survey, $r=0.90$;

236 www.gebco.net/data_and_products/gebco_digital_atlas/3) ${ }^{3}$.

238 Temperature and salinity. We calculated Sea-Surface Temperature (SST), Near-Bottom

239 Temperature (NBT) and salinity (Supplementary Fig. 3) for the period 1980-2012 using the

240 UK Meteorological Office Hadley Centre QUMP_ens_00 standard model for the northwest

241 European shelf seas. Modelled temperatures closely matched data from the Hadley Centre

242 global ocean surface temperature database (HadISST1.1; 92 cells, Pearson's $r=0.84$;

243 www.metoffice.gov.uk/hadobs/hadisst/). Data from the QUMP_ens_00 model were provided

244 as monthly means for $1 \times 1^{\circ}$ cells, enabling mean winter (January-March), summer (July-

245 September) and mean annual values to be calculated (Fig. 1).

247 Fishing pressure. We calculated a spatially-explicit metric of fishing pressure for each 10-

248 year time-slice by combining annual multispecies fishing mortality $(F)$ estimates for North

249 Sea demersal species (mean estimates of regional $F$ for cod, dab, haddock, hake, lemon

250 sole, ling, long rough dab, plaice, saithe and whiting, weighted by spawning-stock biomass,

251 from ICES stock assessments; www.ices.dk/datacentre/StdGraphDB.asp) ${ }^{3}$ with mean otter

252 and beam trawling effort for each $1 \times 1^{\circ}$ cell based on hours of fishing ${ }^{27}$ (Supplementary Fig.

253 3). This integrated metric combining temporal trends in fishing mortality and spatial 
distribution of fishing effort enabled us to test the importance of fishing pressure as a predictor of abundance.

256

257 Identifying key predictors. We used GAM models, coded using the mgcv package in R 258 (www.r-project.org), to test the performance of GAMs for predicting changes in fish species' 259 distribution and identify the importance of different variables to these predictions. The $s$ 260 smooth was used with $k=7$ for all variables to limit the degrees freedom in-line with the 261 number of data points. The Gaussian model was used. Assessment of the plots for each variable using the gam.plot function showed that increasing the $\mathrm{k}$ value did not improve model fit to each variable. The gam.check function was used to check the $\mathrm{k}$ index was above or close to 1 with non-significant $p$ values. Analysis of the residuals showed no obvious deviations from normal distributions, while the response to fitted values relationship was close to linear.

Data from 2000-2009 were used to test sets of variables as this period had the greatest survey intensity. To identify variables that most strongly influenced prediction we first developed a model with all variables (annual temperatures, seasonal temperatures, depth, salinity and fishing), and a subsequent five models each excluding one set of variables (Supplementary Table 1). Sea surface and near bottom temperatures from both the summer and winter were grouped together to characterise seasonal fluctuations. This suite of potentially correlated variables captured the extremes of temperatures that all species may experience at different life stages, and ensured that thermal conditions with and without the seasonal thermocline, annually varying ocean currents and land mass effects are all included. We compared the performance of models based on i) the strength of correlation $r$ between observed and predicted data, ii) weighted $\mathrm{AIC}^{28}$ using data from the AIC function in $\mathrm{R}$, and iii) using generalised cross validation (GCV, through summary.gam in R). Inclusion of 280 interaction terms between depth and seasonal temperature extremes either reduced or had 281 little influence on model performance (Supplementary Table 2 and summaries based on 
Akaike weights in Supplementary Fig. 4).

\section{Model development}

We developed predictive GAMs with a set of variables that were effective across all species.

The correlation coefficient $r$, AIC values and GCV values of modelled and observed data were compared. Across-species inclusion of depth, seasonal temperature, annual temperature, salinity and fishing effort all improved the predictions (Fig. 2a). A key finding from this model development stage is that variables that are readily measured and projected in climate models effectively predict species distributions. On average models that excluded fishing effort were most similar to the all-variable models (Supplementary Table. 1, Fig. 2a). Since this metric had little predictive value, and we have no robust models of future fishing effort, we excluded it when making future predictions.

Training period and predictive performance. To assess the influence of the duration of training data on predictive power, GAMs trained on sets of one, two and three decades of data for each species were used to predict 10 years into the future (Supplementary Fig. 1), and the associations between predicted and known data compared. We also assessed the performance of the model to predict further into the future within the historic records available (Supplementary Fig. 1). We compared predicted with known abundance data for each species for each forecasting period (0 to 30 years).

Forecasting future distributions. We used surface and near bottom annual and seasonal temperature projections from the QUMP_ens_00 model, surface and near bottom salinity, and average depths from surveys between 1980-2012 as the environmental variables for our predictions. We predicted fish abundances for sequential decades from 2000-2009 to 2050-2059 (Supplementary Figs. 5 \& 6) using environmental variables (Supplementary Figs. 3 \& 7), and observed fish abundances from 2000-2009. Throughout the projection period many cells do not experience temperatures outside of the range used to train the 
model (Supplementary Fig. 2). For the widespread species in this study it is therefore likely

311 that at least parts of the population have experienced future conditions. However we

312 recognise that in future projected conditions the climate in some areas of the North Sea will

313 depart from existing variability in the model training period. Since it is not possible to test the

314 model beyond current thermal conditions using know data, some caution should be taken

315 interpreting projections for cells as they begin to experience temperatures beyond those

316 currently in the region (Supplementary Fig. 2).

\section{REFERENCES}

1 Sherman, K. and Hempel, G. (Editors). The UNEP Large Marine Ecosystem Report: A perspective on changing conditions in LMEs of the world's Regional Seas. UNEP Regional Seas Report and Studies No. 182. United Nations Environment Programme. Nairobi, Kenya (2009).

2 Perry, A. L., Low, P. J., Ellis, J. R. \& Reynolds, J. D. Climate change and distribution shifts in marine fishes. Science 308, 1912-1915 (2005).

3 Simpson, S. D. et al. Continental shelf-wide response of a fish assemblage to rapid warming of the sea. Curr. Biol. 21, 1565-1570 (2011).

4 Cheung, W. W., Lam, V. W., Sarmiento, J. L., Kearney, K., Watson, R. \& Pauly, D. Projecting global marine biodiversity impacts under climate change scenarios. Fish Fish. 10, 235-251 (2009).

5 Jones, M. C. et al. Predicting the impact of climate change on threatened species in UK waters. PLoS ONE 8, e54216 (2013).

6 Smith, T. M., Reynolds, R. W., Peterson, T. C. \& Lawrimore, J. Improvements to NOAA's historical merged land-ocean surface temperature analysis (1880-2006). J. Climate 21, 2283-2296 (2008). 
7 Beaugrand, G., Reid, P. C., Ibanez, F., Lindley, J. A. \& Edwards, M. Reorganization of North Atlantic marine copepod biodiversity and climate. Science 296, 1692-1694

8 Edwards, M. \& Richardson, A. J. Impact of climate change on marine pelagic phenology and trophic mismatch. Nature 430, 881-884 (2004).

9 Genner, M. J. et al. Temperature-driven phenological changes within a marine larval fish assemblage. J. Plankton Res. 32, 699-708 (2010).

10 Beaugrand, G., Brander, K. M., Lindley, J. A., Souissi, S. \& Reid, P. C. Plankton effect on cod recruitment in the North Sea. Nature 426, 661-664 (2003).

11 Durant, J. M., Hjermann, D. O., Ottersen, G. \& Stenseth, N. C. Climate and the match or mismatch between predator requirements and resource availability. Climate Res. 33, 271-283 (2007).

12 Beare, D. J. et al. Long-term increases in prevalence of North Sea fishes having southern biogeographic affinities. Mar. Ecol. Prog. Ser. 284, 269-278 (2004).

13 Dulvy, N. K. et al. Climate change and deepening of the North Sea fish assemblage: a biotic indicator of warming seas. J. Appl. Ecol. 45, 1029-1039 (2008).

14 Cheung, W. W. L., Watson, R. \& Pauly, D. Signature of ocean warming in global fisheries catch. Nature 497, 365-369 (2013).

15 Araujo, M. B., Pearson, R. G., Thuiller, W. \& Erhard, M. Validation of species-climate impact models under climate change. Glob. Change Biol. 11, 1504-1513 (2005).

16 Cheung, W. W. L. et al. Large-scale redistribution of maximum fisheries catch potential in the global ocean under climate change. Glob. Change Biol. 16, 24-35 (2010).

17 de Madron, X. D. et al. Marine ecosystems' responses to climatic and anthropogenic forcings in the Mediterranean. Prog. Oceanogr. 91, 97-166 (2011).

18 Dingsor, G. E., Ciannelli, L., Chan, K.-S., Ottersen, G. \& Stenseth, N. C. Density dependence and density independence during the early life stages of four marine fish stocks. Ecology 88, 625-634 (2007). 
19 Hedger, R. et al. Analysis of the spatial distributions of mature cod (Gadus morhua) and haddock (Melanogrammus aeglefinus) abundance in the North Sea (1980-1999) using generalised additive models. Fish. Res. 70, 17-25 (2004).

20 Belanger, C. L. et al. Global environmental predictors of benthic marine biogeographic structure. P. Natl. Acad. Sci. USA 109, 14046-14051 (2012).

21 Engelhard, G. H., Righton, D. A. and Pinnegar, J. K. Climate change and fishing: a century of shifting distribution in North Sea cod. Glob. Change Biol. 20, 2473-2483 (2014).

22 Neat, F. C. \& Righton, D. Warm water occupancy by North Sea cod. P. Roy. Soc. Lond. B Bio. 274, 789-798 (2007).

23 Neuheimer, A. B., Thresher, R. E., Lyle, J. M. \& Semmens, J. M. Tolerance limit for fish growth exceeded by warming waters. Nature Clim. Change 1, 110-113 (2011).

24 Donelson, J. M., Munday, P. L., McCormick, M. I. \& Pitcher, C. R. Rapid transgenerational acclimation of a tropical reef fish to climate change. Nature Clim. Change 2, 30-32, (2012).

25 Crozier, L. G. \& Hutchings, J. A. Plastic and evolutionary responses to climate change in fish. Evol. Apps. 7, 68-87 (2014).

26 Jennings, S. \& Blanchard, J. L. Fish abundance with no fishing: predictions based on macroecological theory. J. Anim. Ecol. 73, 632-642 (2004).

27 Jennings, S. et al. Fishing effects in northeast Atlantic shelf seas: patterns in fishing effort, diversity and community structure. III. International trawling effort in the North Sea: an analysis of spatial and temporal trends. Fish. Res. 40, 125-134 (1999).

28 Burnham, K. P. and D. R. Anderson. Model Selection and Multimodel Inference. (Springer-Verlag, New York, 2002).

\section{AUTHOR INFORMATION}

Correspondence and requests for materials should be addressed to S.D.S. (S.Simpson@exeter.ac.uk). 
ACKNOWLEDGEMENTS

393 We thank staff of the Centre for Environment, Fisheries and Aquaculture Science UK

394 (Cefas) and all contributors to the International Council for the Exploration of the Sea (ICES)

395 International Bottom Trawl Survey (IBTS) for collecting and providing survey data. We thank

396 Sandrine Vaz for training in GAM modeling in R and David Maxwell for statistical guidance.

397 This work was supported by a Natural Environment Research Council (NERC) / Department

398 for Environment Food and Rural Affairs (Defra) Sustainable Marine Bioresources award

399 (NE/F001878/1), with additional support from a NERC KE Fellowship (S.D.S;

400 NE/J500616/2), NERC-Cefas CASE PhD Studentship (L.A.R; NE/L501669/1), Great

401 Western Research (M.J.G.), Defra (S.J. and J.L.B.), NERC Oceans 2025 (M.J.G. and

402 D.W.S), The Worshipful Company of Fishmongers (D.W.S.), and a Marine Biological

403 Association Senior Research Fellowship (D.W.S.).

404

405

AUTHOR CONTRIBUTIONS

406

M.J.G. and M.P.J. conceived the research; S.J., J.L.B. and D.W.S. contributed to project

407

development; S.D.S. and S.J. pre-processed fisheries agency data; L.A.R. and J.T. pre-

408

processed climate data; S.D.S., M.J.G., L.A.R., M.P.J. and S.J. designed the analysis; L.A.R

409

and S.D.S. conducted the analysis; S.D.S., L.A.R and M.J.G. prepared the initial manuscript

410 and all authors contributed to revisions.

411

412 COMPETING FINANCIAL INTERESTS STATEMENT

413 The authors declare no competing financial interests.

414

415

416

FIGURE LEGENDS

417 
418 Figure 1. Physical environment of the North Sea. (a) Bathymetry with an overlay showing

419 locations of the $841 \times 1^{\circ}$ latitude-longitude cells in which fish abundance, distribution and sea

420 temperature were reported and predicted; (b) mean Sea-Surface Temperature (SST, red)

421 and Near-Bottom Temperature (NBT, black) in the study cells from 1980-2060 in summer

422 (July-September, solid line) and winter (January-March, dashed line) from the

423 QUMP_ens_00 northwest European shelf seas climate model. Mean decadal values (as

424 used in the model) are overlaid in the corresponding colours for SST and NBT for each

425 season.

426

427 Figure 2. Predictive ability of Generalised Additive Models (GAMs). (a) Fits of predicted to

428 observed species abundance using 2000-2009 data. Variables were sequentially removed.

429 Model fits were evaluated using correlation (mean \pm SE Pearson's $r$ coefficient across

430 species) and weighted Akaike Information Criterion (AIC: mean \pm SE across species). (b)

431 Duration of training data and predictive performance of GAMs using depth and seasonal

432 temperatures. Correlations (mean \pm SE Pearson's $r$ coefficient across species) indicate no

433 improvement in performance with longer time-series. (c) Relationship between known data

434 and GAM predictions using depth, salinity and seasonal and annual temperature, for

435 decades beyond GAM training period.

436

437 Figure 3. Observed and predicted abundances of eight focal species along depth, latitude

438 and mean annual Near-Bottom Temperature (NBT) and Sea-Surface Temperature (SST)

439 gradients. Analyses were based on both the summer and winter survey datasets.

440 Distribution averages for each time period are shown using arrows of corresponding colours

441 along the $x$-axis. 


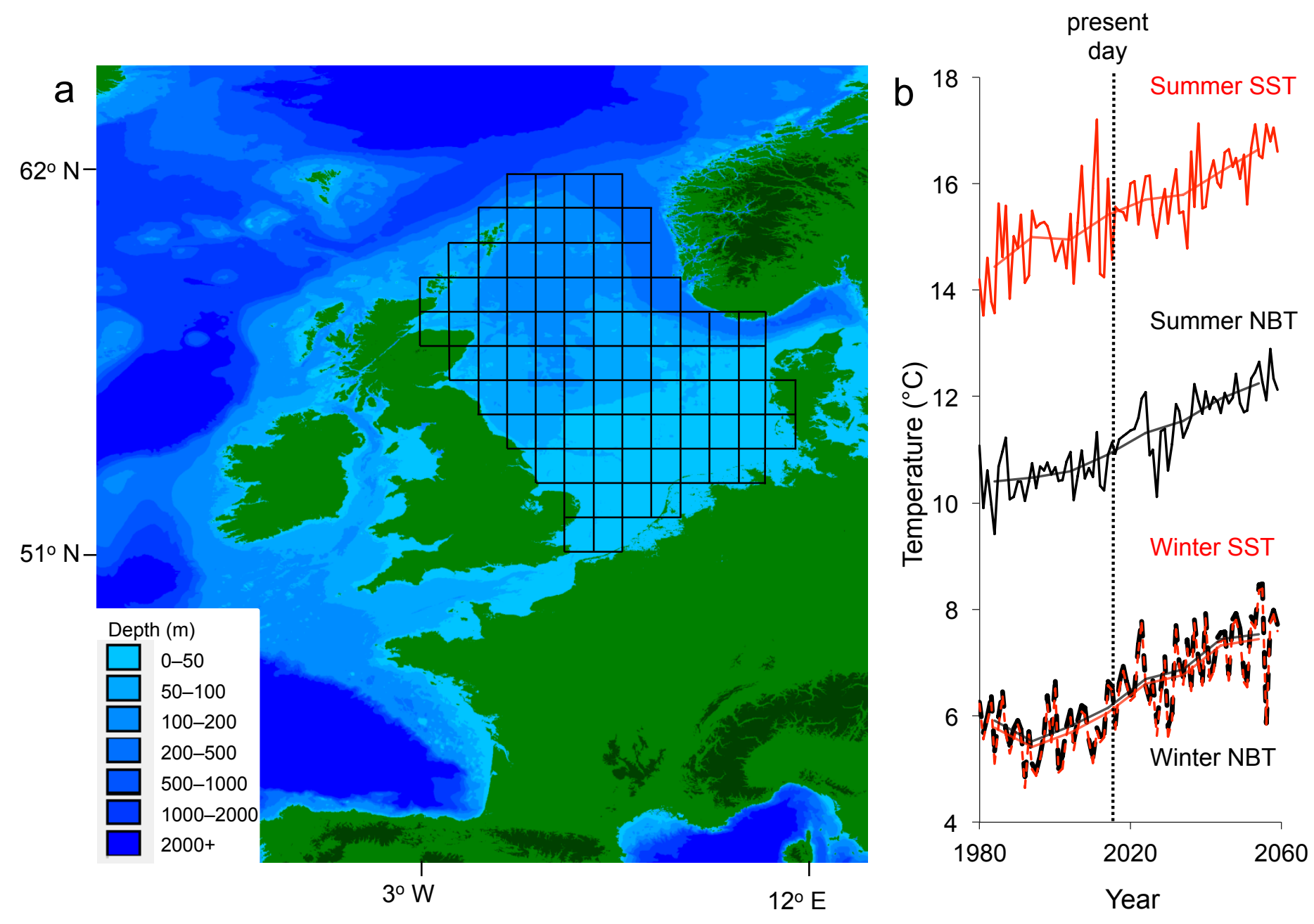



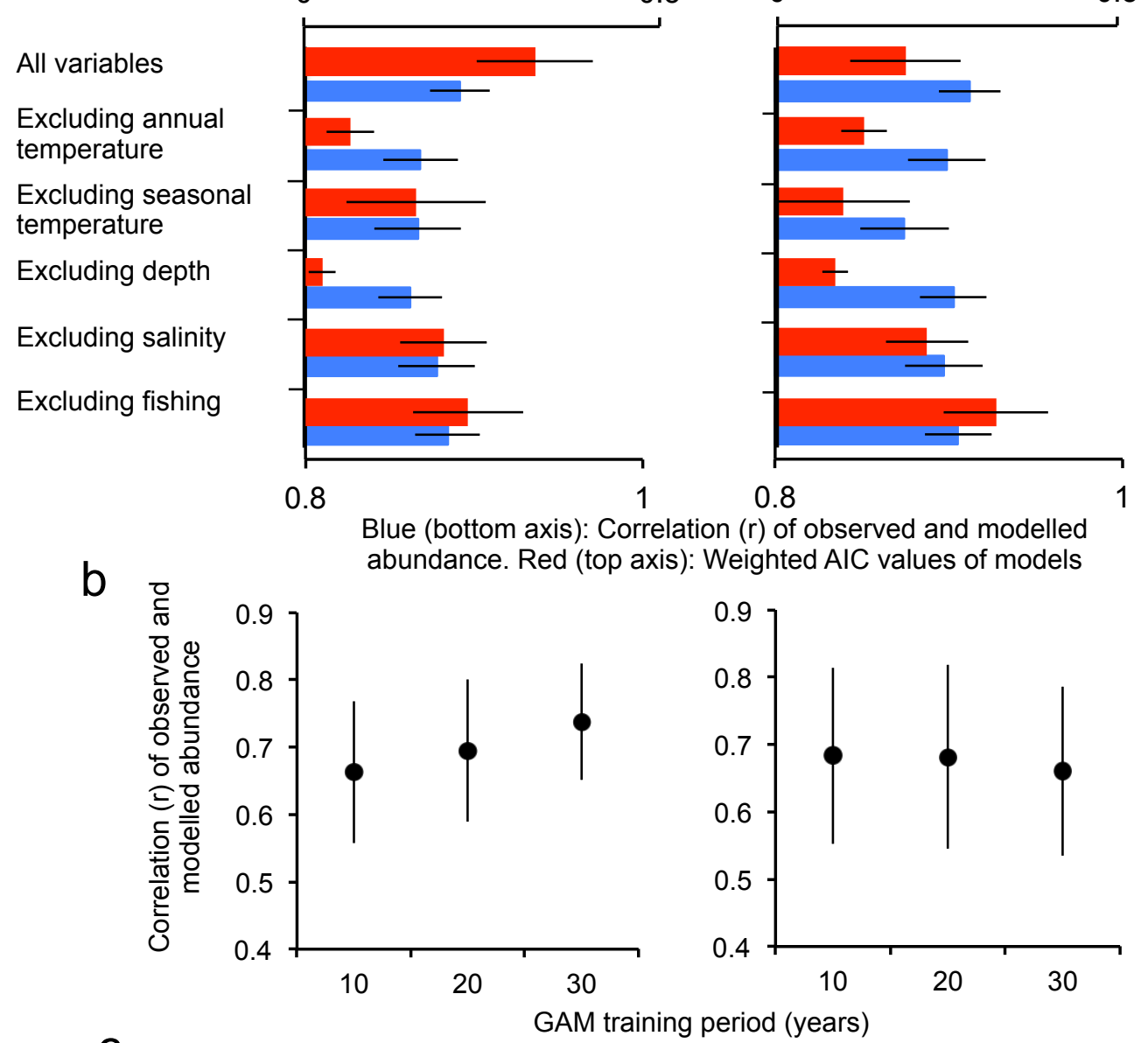

C

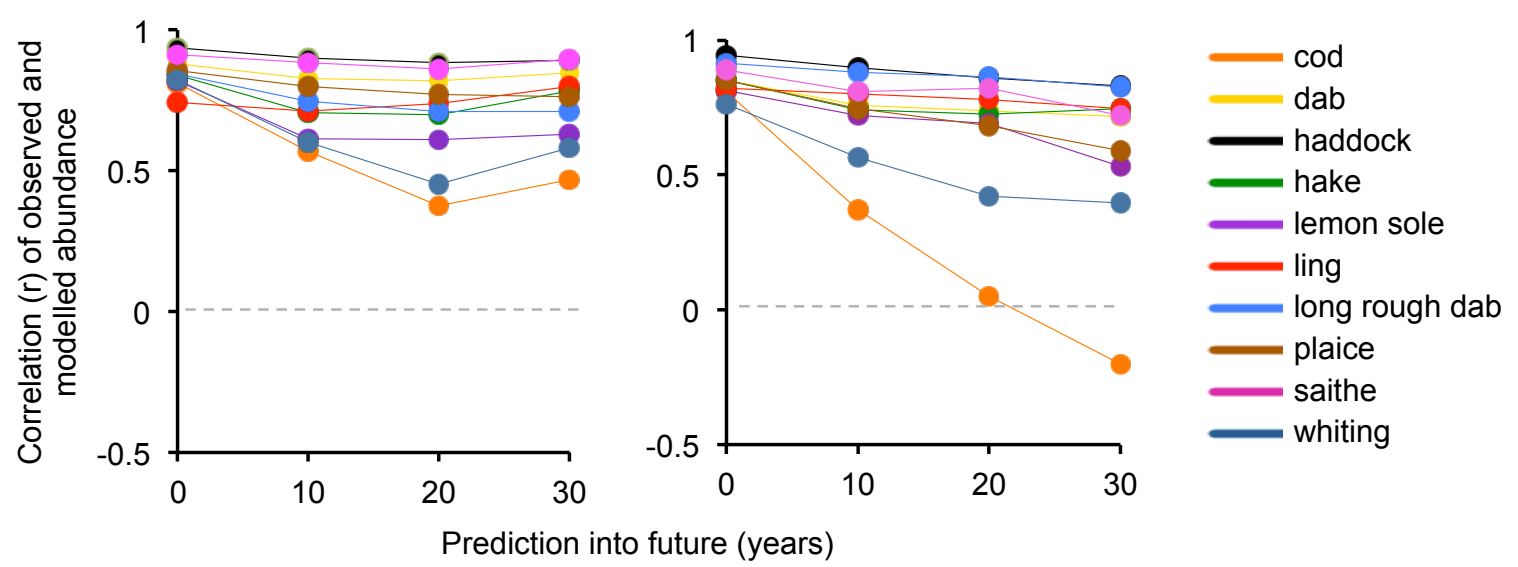


Summer survey

dab

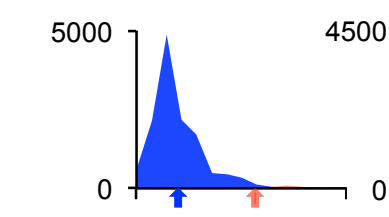

haddock
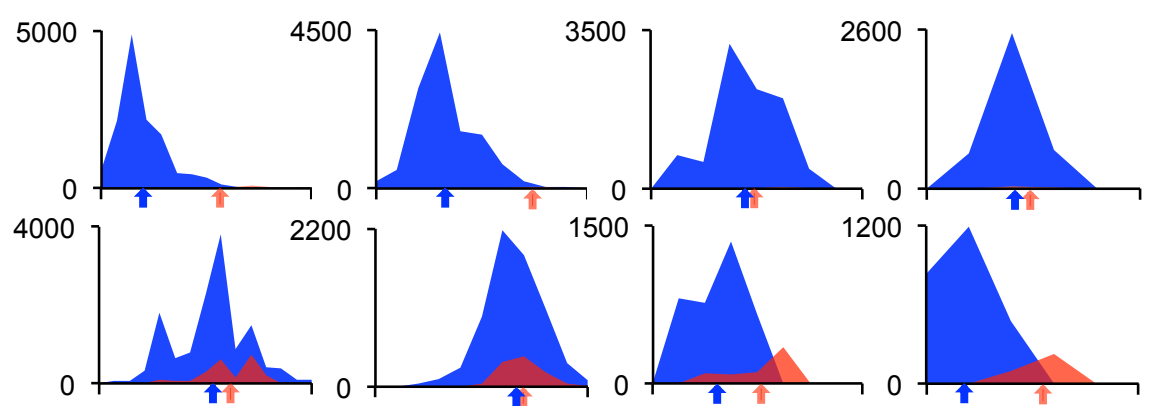

hake
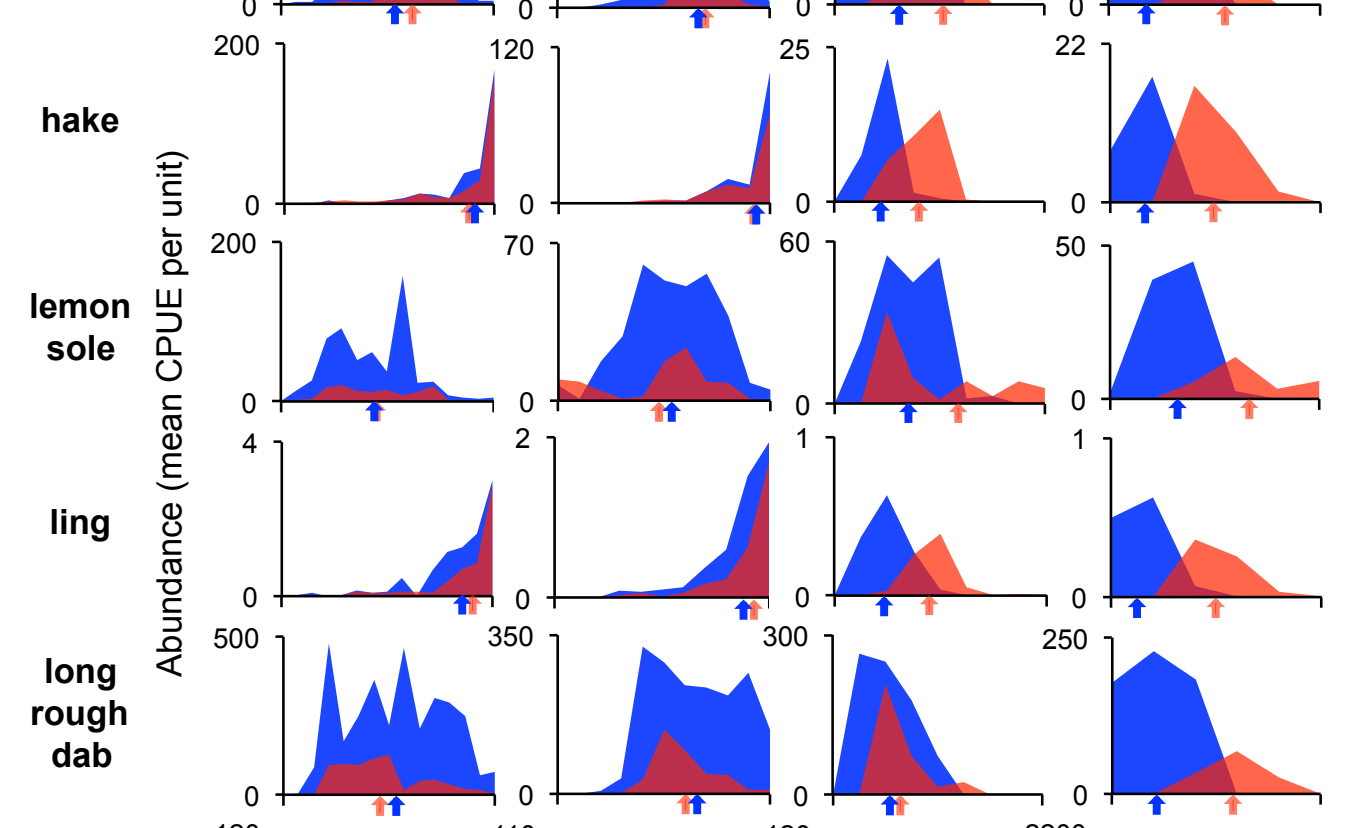

plaice
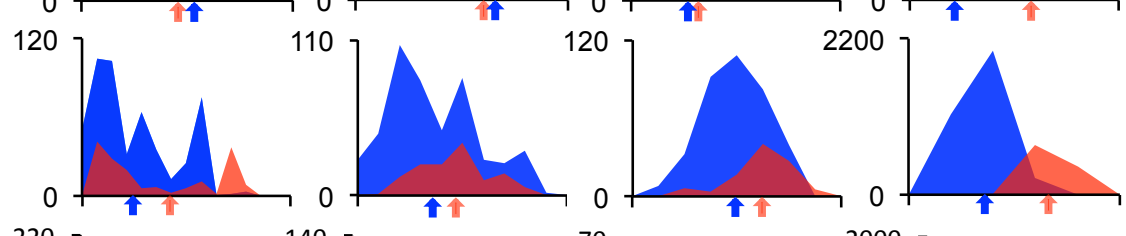

saithe

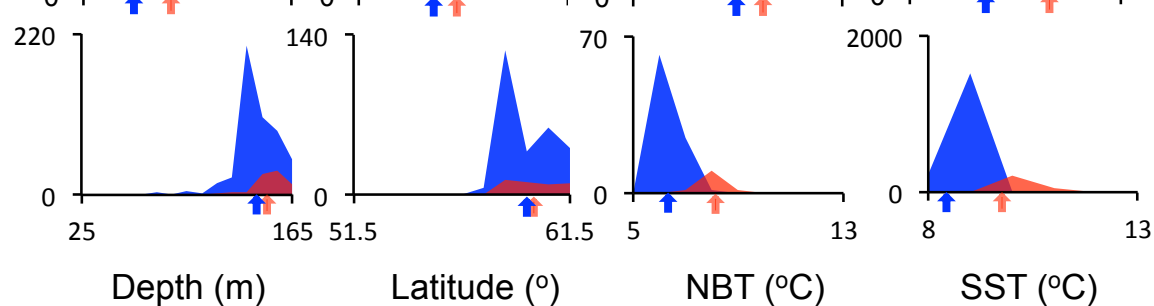

Observed distributions 2000-2009
Winter survey
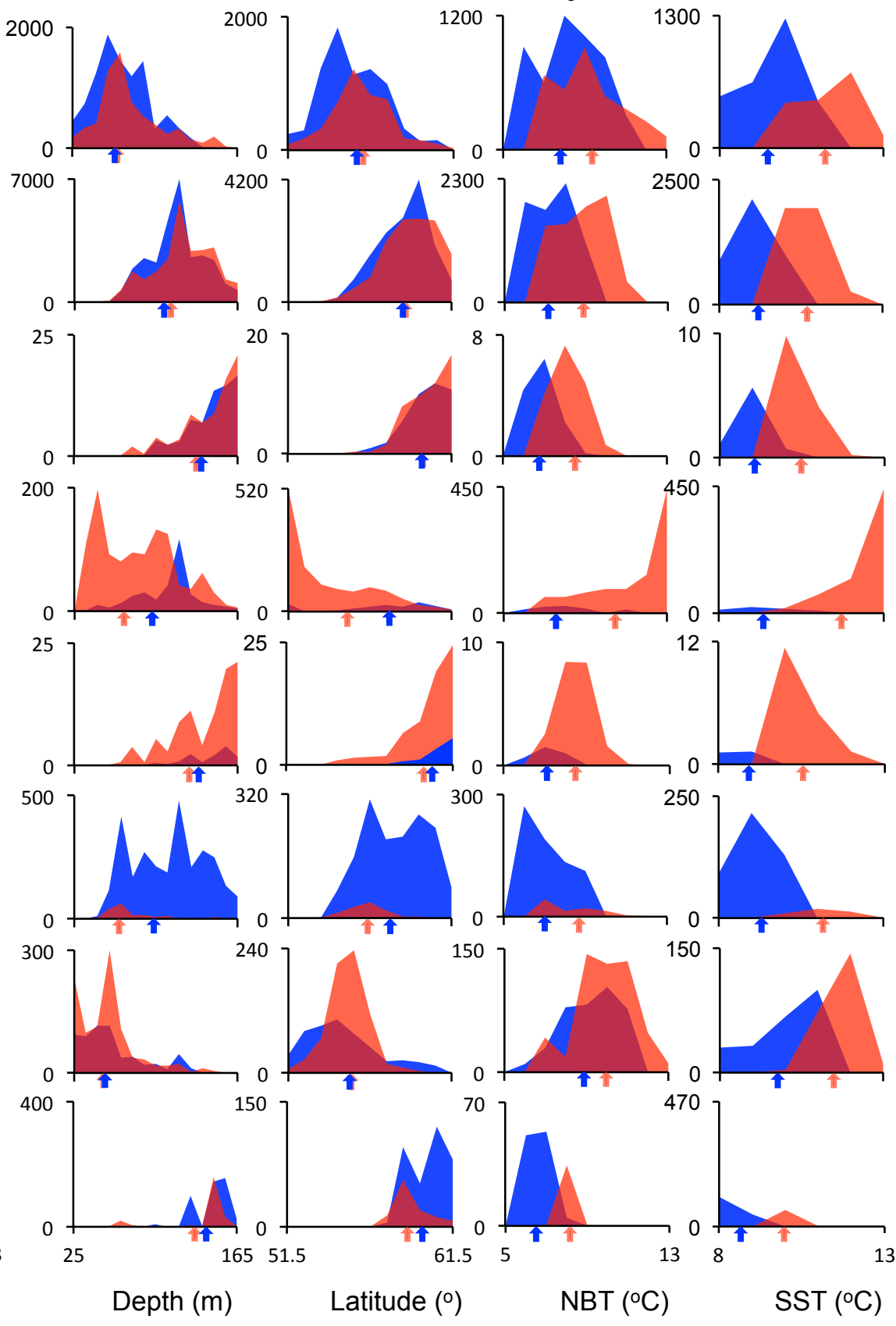